\title{
EAU, AUA and NICE Guidelines on Surgical and Minimally Invasive Treatment of Benign Prostate Hyperplasia: A Critical Appraisal of the Guidelines Using the AGREE-II Tool
}

\author{
Dmitry Enikeev $^{a}$ Vincent Misrai $^{b}$ Enrique Rijo ${ }^{c}$ Roman Sukhanov ${ }^{a}$ \\ Denis Chinenov ${ }^{a}$ Magomed Gazimiev ${ }^{\mathrm{a}}$ Mark Taratkin $^{\mathrm{a}}$ Camilla Azilgareeva $^{\mathrm{d}}$ \\ Andrey Morozov $^{a}$ Thomas R.W. Herrmann ${ }^{\text {e, }}$ Petr Glybochko ${ }^{a}$ \\ anstitute for Urology and Reproductive Health, Sechenov University, Moscow, Russia; bepartment of Urology, \\ Clinique Pasteur, Toulouse, France; 'Department of Urology, Hospital Quirón Salud, Barcelona, Spain; 'International \\ School "Medicine of the Future", Sechenov University, Moscow, Russia; eDepartment of Urology, Spital Thurgau AG, \\ Frauenfeld, Switzerland; fDepartment of Urology, Hanover Medical School (MHH), Hanover, Germany
}

\section{Keywords}

Appraisal of Guidelines for Research and Evaluation .

Benign prostate hyperplasia - Minimally invasive

treatment · Guidelines

\begin{abstract}
Objective: To critically appraise the methodological rigour of the clinical practice guidelines (CPGs) vis-à-vis BPH surgery as used by specialist research associations in the US, Europe and UK, and to compare whether the guidelines cover all or only some of the available treatments. Methods: The current guidelines issued by the EUA, AUA and NICE associations have been analyzed by 4 appraisers using the AGREE-II instrument. We also compared the recommendations given in the guidelines for surgical and minimally invasive treatment to find out which of these CPGs include most of the available treatment options. Results: According to the AGREE II tool, the median scores of domains were: domain 1
\end{abstract}

karger@karger.com www.karger.com/uin

Karger $\stackrel{\text { ' }}{5}$

GOPEN ACCESS
(C) 2021 The Author(s)

Published by S. Karger AG, Basel

This is an Open Access article licensed under the Creative Commons Attribution-NonCommercial-4.0 International License (CC BY-NC) (http://www.karger.com/Services/OpenAccessLicense), applicable to the online version of the article only. Usage and distribution for commercial purposes requires written permission. scope and purpose $66.7 \%$, domain 2 stakeholder involvement $50.0 \%$, domain 3 rigor of development $65.1 \%$, domain 4 clarity of presentation $80.6 \%$, domain 5 applicability $33.3 \%$, domain 6 editorial independence $72.9 \%$. The overall assessment according to AGREE II is $83.3 \%$. The NICE guideline scored highest on 5 out of 6 domains and the highest overall assessment score (91.6\%). The EAU guideline scored lowest on 4 out of 6 domains and has the lowest overall assessment score (79.1\%). Conclusions: The analyzed CPGs comprehensively highlight the minimally invasive and surgical treatment options for BPH. According to the AGREE II tool, the domains for clarity of presentation and editorial independence received the highest scores. The stakeholder involvement and applicability domains were ranked as the lowest. Improving the CPG in these domains may help to improve the clinical utility and applicability of CPGs.

(C) 2021 The Author(s)

Published by S. Karger AG, Basel
Correspondence to:

Dmitry Enikeev, dvenikeev@gmail.com 


\section{Introduction}

Benign Prostatic Obstruction (BPO) due to Benign Prostatic Hyperplasia (BPH) is one of the most common urological diseases and often requires surgical treatment [1-3]. A number of less invasive procedures have come to light recently allowing us to pursue a more personalized approach. In this regard, various randomized controlled studies (RCTs), systematic reviews and meta-analyses have been conducted. Evidence-based data supporting the effectiveness of these procedures led to them being reflected in the recently updated (up to July 2020) clinical practice guidelines (CPGs).

There are a number of tools that can be used to assess the quality of the guidelines. One of the most validated and extensively used is the AGREE (Appraisal of Guidelines for Research and Evaluation) instrument. It was developed to address the issue of variability in the quality of the guidelines and in the development process and reporting $[4,5]$.

The purpose of the present study was to critically appraise the methodological rigour and transparency of CPGs issued by the leading organizations on the minimally-invasive treatment of BPO using the AGREE II instrument and to evaluate the comprehensiveness of surgical and minimally invasive $\mathrm{BPH}$ treatment methods as presented in the CPGs.

\section{Materials and Methods}

We included recent updates of full texts of clinical guidelines for surgical minimally invasive treatment of $\mathrm{BPH}$. The guidelines by any other national associations or non-English guidelines were excluded. The largest English-speaking urological societies' guidelines were used. In this analysis, current guidelines from the European Association of Urology (EUA) [6], American Urological Association (AUA) [7] and National Institute for Health and Care Excellence (NICE) [8] were included. We used AGREE-II tool (version 2, December 2017 update) to assess the quality of these guidelines.

AGREE-II instrument consists of 23 items that are scored on a 7 -point scale ranging from 1 (strongly disagree, which means that no relevant information is provided) to 7 (strongly agree, which means that the quality of reporting is excellent). These 23 items are grouped into 6 domains [5].

Final domain scores were calculated by summing up all the item scores within the domain and by scaling the total as a percentage of the maximum possible score for that domain [5].

Four urologists (optimal according to AGREE II) with differing levels of expertise (1- $<5$ years, 2-3- 5-10 years and 4- $>15$ years) were trained to use the AGREE II rating system (the training tools are available online at www.agreetrust.org). All the participants practice outside the jurisdictions of the guidelines (EU, USA, UK).
The participants independently appraised and scored each guideline. The scores were then expressed as standardized domain scores on a percent scale ranging from 0 to $100 \%$ (a percentage of the maximum possible score for each particular domain).

The performance in each domain was evaluated using a threshold of $60 \%$. In addition, the total score (expressed as median and IQR) of the guidelines and the domains was calculated. Domain scores were categorized as good ( $\geq 80 \%)$, acceptable (60-79\%), low $(40-59 \%)$, or very low $(<40 \%)[9,10]$.

\section{Results}

\section{Basic Features of Included Guidelines}

European Association of Urology

The EAU guideline [6] latest version was published in 2020 and is updated annually. Members of the Panel incorporated into the guidelines for ease of evidence acquisition and synthesis strictly systematic reviews with metaanalysis, RCTs, and prospective non-randomized comparative studies. All collected data are assessed and graded according to the GRADE approach. Based on these forms, the team determined how strong the rating was and assigned each recommendation a "strong" or "weak" rating.

\section{American Urological Association}

The AUA guideline [7] latest version was published in 2019 , an update of the previous one released in 2010. The evidence review team identified eligible RCTs, clinical controlled trials (CCTs), systematic reviews/meta-analyses, and observational studies. The team also used the Cochrane Collaboration's tool for assessing risk of bias. Overall quality of evidence was evaluated using the GRADEpro software. The quality of evidence (graded from A-C) and Linking statement type (strong, moderate and conditional recommendations, clinical principle and expert opinion) are assigned to each recommendation.

National Institute for Health and Care Excellence

The NICE [8] guideline was published in 2010, updated in 2015 and some additional files were released in 2019. The development group assessed the quality using the GRADE system and graded it according to NICE Guidelines Manual. The NICE development group does not assign strength rating or linking statement type, etc. They explain each recommendation by giving information about the values of different outcomes, clinical benefits and harms, economic considerations, quality of evidence (by discussing it) and some other considerations. 
Table 1. AGREE results for each domain and overall assessment

\begin{tabular}{llll}
\hline & EAU, \% & AUA, \% & NICE, \% \\
\hline Scope and purpose & 56.9 (Low) & 66.7 (Acceptable) & 94.4 (Good) \\
Stakeholder involvement & 25.0 (Low) & 50.0 (Low) & 61.1 (Acceptable) \\
Rigor of development & 62.5 (Acceptable) & 65.1 (Acceptable) & 83.9 (Good) \\
Clarity of presentation & 91.7 (Good) & 80.6 (Good) & 79.2 (Acceptable) \\
Applicability & 32.3 (Low) & 33.3 (Low) & 56.3 (Low) \\
Editorial independence & 79.2 (Acceptable) & 60.4 (Acceptable) & 72.9 (Acceptable) \\
Overall assessment & $\mathbf{7 9 . 1 ( A c c e p t a b l e ) ~}$ & $\mathbf{8 3 . 3 ( G o o d )}$ & $\mathbf{9 1 . 6}$ (Good) \\
I would recommend this guideline for use & All-Yes & All-Yes & All-Yes \\
\hline
\end{tabular}

AGREE-II Evaluation Results

Domain 1 Scope and Purpose

The AGREE-II quality scores for domain 1 ranged from 56.9 to $94.4 \%$ with a median score (IQR) of $66.7 \%$ (61.8-80.5\%). AUA and NICE scores were $>60 \%$ in the domain 1 . However, the score of EAU was $<60 \%$ with the lower scores in objectives description, health questions and study populations.

Domain 2 Stakeholder Involvement

The AGREE II quality scores for domain 2 ranged from 25.0 to $61.1 \%$ with a median score (IQR) of $50.0 \%$ (37.5-55.6\%). The included CPGs reported minimal information about patient's preferences or target users of the guidelines and subsequently were assigned low scores.

Domain 3 Rigor of Development

The AGREE II quality scores for domain 3 ranged from 62.5 to $83.9 \%$ with a median score (IQR) of $65.1 \%$ (63.8-74.5\%). All CPGs scores were $>60 \%$ in the domain 3 . However, the most common weaknesses across all CPGs were the following: the methods for formulating the recommendations and external review.

Domain 4 Clarity of Presentation

The AGREE II quality scores for domain 4 ranged from 79.2 to $91.7 \%$ with a median score (IQR) of $80.6 \%$ (79.9-86.2\%). This domain was well-addressed in all the CPGs that were included. Recommendations were informative, specific, and key issues were easily identifiable. Moreover, the highest median score was in this domain (median $80.6 \%$ ) with minimal variability.

Domain 5 Applicability

The AGREE II quality scores for domain 5 ranged from 32.3 to $56.3 \%$ with a median score (IQR) of $33.3 \%$ (32.8-44.8\%). The NICE guideline received the highest score. However, none of the CPGs received a score above 60\% (EAU-32.3\%; AUA-33.3\%; NICE-56.3\%). The information regarding barriers, facilitators, the monitoring and auditing of criteria was missing in most of the CPGs. This domain is characterized by the lowest median score of $33.3 \%$, with a medium variability.

Domain 6 Editorial Independence

The AGREE II quality scores for domain 6 ranged from 60.4 to $79.2 \%$ with a median score (IQR) of $72.9 \%$ (66.6-76.1\%). All the guidelines scored $>60 \%$ and provided adequate information about competing interests. EAU guidelines include a conflict of interest disclosure for each panel member which states that no external sources of funding were involved. As for the AUA guidelines, there is also a conflict of interest disclosure which must be completed by each co-author. Where the NICE guidelines is concerned, a conflict of interest is listed not only for the panel members, but also for the studies which were assessed to develop the guidelines.

The difference between the appraisers' score within each domain was not $>2$ points (at 7-point scale). The median score (IQR) of overall assessment is $83.3 \%$ (79.1$91.6 \%)$. The highest score was received by NICE guidelines (91.6\%) and the lowest-EAU guidelines (79.1\%). Overall, the NICE guideline scored highest on 5 out of the 6 domains, the EAU guideline scored lowest on 4 out of the 6 domains with the AGREE II instrument (Table 1).

\section{Surgical Treatment for $\mathrm{BPH}<80 \mathrm{~cm}^{3}$ (Table 2)}

Transurethral Resection of the Prostate (TURP) and

Transurethral Incision of the Prostate (TUIP)

All the included guidelines state bi- or monopolar TURP as the standard option for the treatment of men with $\mathrm{BPH}$. Only the EAU guideline recommends this method for patients with prostate volume not $>80 \mathrm{~cm}^{3}$. Beyond that, the associations recommend using transure- 
Table 2. Surgery recommendations

\begin{tabular}{|c|c|c|}
\hline Method & Association & Indication \\
\hline \multirow[t]{3}{*}{ TUIP } & EAU 2020 & $\begin{array}{l}\text { Prostate volume }<30 \mathrm{~cm}^{3} \\
\text { Without a middle lobe }\end{array}$ \\
\hline & AUA 2019 & Prostate volume $\leq 30 \mathrm{~cm}^{3}$ \\
\hline & NICE 2015 & $\begin{array}{l}\text { Prostate volume }<30 \mathrm{~cm}^{3} \\
\text { As an alternative to other types of surgery }\end{array}$ \\
\hline TURP & AUA 2019 & $\begin{array}{l}\text { As a treatment option for men with LUTS } \\
\text { Monopolar or bipolar approach (depending on specialist's expertise with these } \\
\text { techniques) }\end{array}$ \\
\hline \multirow{2}{*}{ Simple prostatectomy } & AUA 2019 & $\begin{array}{l}\text { For patients with large prostates } \\
\text { Consider open, laparoscopic or robotic assisted SP, depending on surgeon's expertise } \\
\text { with these techniques }\end{array}$ \\
\hline & NICE 2015 & $\begin{array}{l}\text { Prostate volume }>80 \mathrm{~cm}^{3} \\
\text { As an alternative to TURP, TUVP or HoLEP }\end{array}$ \\
\hline \multirow[t]{2}{*}{ Laser enucleation } & EAU 2020 & $\begin{array}{l}\text { HoLEP } \\
\text { As an alternative to TURP or OP }\end{array}$ \\
\hline & & $\begin{array}{l}\text { 120-W } 980 \mathrm{~nm} \text { diode laser or } 1,318 \mathrm{~nm} \text { diode laser } \\
\text { As a comparable alternative to TURP or bipolar enucleation }\end{array}$ \\
\hline
\end{tabular}

thral incision of the prostate (TUIP) in case of small glands $\left(<30 \mathrm{~cm}^{3}\right)$.

\section{Vaporization}

The EAU, AUA and NICE guidelines agree on the use of the electro- or laser vaporization for BPO treatment. The EAU guidelines recommend laser vaporization primarily for patients with prostate volume $30-80 \mathrm{~cm}^{3}$ as an alternative to TURP. The same indications apply for bipolar transurethral vaporization (TUVP). The AUA guidelines do not mention any restrictions on vaporization by prostate size. The NICE working group reported that bipolar TUVP, transurethral vaporesection of the prostate (TUVRP) and laser vaporization techniques may be used only as a part of clinical trials in comparison with TURP. The only technique with a clear recommendation is vaporization with GreenLight XPS laser in non-highrisk patients (with low bleeding risk, prostate size $<100$ $\mathrm{cm}^{3}$ and without urinary retention).

\section{Surgical Treatment for $\mathrm{BPH}>80 \mathrm{~cm}^{3}$ (Table 2)}

Simple Prostatectomy (SP)

In their guidelines, the Associations under consideration describe open SP as a treatment option for large pros- 
Table 2 (continued)

\begin{tabular}{|c|c|c|}
\hline Method & Association & Indication \\
\hline \multirow[t]{9}{*}{$\begin{array}{l}\text { Vaporization and its } \\
\text { modifications }\end{array}$} & \multirow[t]{5}{*}{ EAU 2020} & $\begin{array}{l}80-\mathrm{W} 532-\mathrm{nm} \text { KTP laser vaporization } \\
\text { Prostate volume } 30-80 \mathrm{~cm}^{3} \\
\text { As an alternative to TURP }\end{array}$ \\
\hline & & $\begin{array}{l}120-\mathrm{W}, 180-\mathrm{W} 532-\mathrm{nm} \mathrm{LBO} \text { laser vaporization } \\
\text { Prostate volume } 30-80 \mathrm{~cm}^{3} \\
\text { As an alternative to TURP }\end{array}$ \\
\hline & & $\begin{array}{l}\text { 120-W } 980 \mathrm{~nm} \text { diode laser vaporization } \\
\text { As a comparable alternative to TURP }\end{array}$ \\
\hline & & $\begin{array}{l}\text { ThuVARP } \\
\text { As an alternative to TURP }\end{array}$ \\
\hline & & $\begin{array}{l}\text { Bipolar TUVP } \\
\text { Prostate volume } 30-80 \mathrm{~cm}^{3} \\
\text { As an alternative to TURP }\end{array}$ \\
\hline & AUA 2019 & $\begin{array}{l}\text { PVP using } 120 \mathrm{~W} \text { or } 180 \mathrm{~W} \text { platforms } \\
\text { Treatment of LUTS attributed to BPH }\end{array}$ \\
\hline & \multirow[t]{3}{*}{ NICE 2015} & $\begin{array}{l}\text { Monopolar TUVP } \\
\text { For managing voiding LUTS }\end{array}$ \\
\hline & & $\begin{array}{l}\text { Laser vaporization techniques, bipolar TUVP or monopolar or bipolar TUVRP } \\
\text { As part of a RCT that compares these techniques with TURP }\end{array}$ \\
\hline & & $\begin{array}{l}\text { GreenLight XPS in non-high-risk patients } \\
\text { Is at least as effective in these patients as TURP } \\
\text { As a day-case procedure, following appropriate service redesign }\end{array}$ \\
\hline \multirow{3}{*}{$\begin{array}{l}\text { Patients on } \\
\text { antiplatelet or } \\
\text { anticoagulant therapy }\end{array}$} & EAU 2020 & $\begin{array}{l}\text { Laser vaporization of the prostate using } 80-\mathrm{W} \text { KTP, } 120 \text { - or } 180-\mathrm{W} \text { LBO lasers } \\
\text { Prostate volume }<80 \mathrm{~cm}^{3}\end{array}$ \\
\hline & AUA 2019 & $\begin{array}{l}\text { HoLEP } \\
\text { PVP } \\
\text { ThuLEP }\end{array}$ \\
\hline & NICE 2015 & $\mathrm{~N} / \mathrm{A}$ \\
\hline
\end{tabular}

HoLEP, Holmium laser enucleation of the prostate; KTP, Potassium-Titanyl-Phosphate; LBO, Lithium Borat; LUTS, Lower Urinary Tract Symptoms; OP, Open prostatectomy; PVP, Photoselective Vaporization of the Prostate; TUIP, Transurethral incision of the prostate; TURP, Transurethral resection of the prostate; TUVP, Transurethral Vaporization of Prostate; TUVRP, transurethral vaporesection of the prostate; ThuLEP, Thulium laser enucleation of the prostate; ThuVARP, Tm; YAG, laser vaporesection; ThuVEP, Thulium VapoEnucleation of the prostate; AUA, American Urological Association; EAU, European Association of Urology; NICE, National Institute for Health and Care Excellence. 
Table 3. Minimally invasive treatment indications with some comment from guidelines

\begin{tabular}{|c|c|c|}
\hline Method & Association & Indication/comments \\
\hline \multirow[t]{3}{*}{ Prostatic urethral lift } & EAU 2020 & $\begin{array}{l}\text { Prostate volume }<70 \mathrm{~cm}^{3} \\
\text { Absence of middle lobe } \\
\text { Interested in preserving ejaculatory function }\end{array}$ \\
\hline & AUA 2019 & $\begin{array}{l}\text { Prostate volume }<80 \mathrm{~cm}^{3} \\
\text { Verified absence of an obstructive middle lobe } \\
\text { To eligible patients concerned with erectile and ejaculatory function } \\
\text { Patients should be informed of its inferiority to TURP }\end{array}$ \\
\hline & NICE 2015 & $\begin{array}{l}\text { Prostate volume }<100 \mathrm{~cm}^{3} \\
\text { Patients age }>50 \text { years } \\
\text { Without an obstructing middle lobe } \\
\text { As an alternative to current surgical procedures for use in a day-case setting }\end{array}$ \\
\hline Aquablation & NICE 2015 & $\begin{array}{l}\text { The evidence on efficacy is limited in quantity } \\
\text { The procedure should only be used with special arrangements for clinical governance, } \\
\text { consent, and audit or research } \\
\text { The procedure should only be done by clinicians who have been trained in the technique }\end{array}$ \\
\hline $\begin{array}{l}\text { Prostatic artery } \\
\text { embolization }\end{array}$ & EAU 2020 & $\begin{array}{l}\text { For patients who wish to consider minimally invasive treatment options and accept less } \\
\text { optimal objective outcomes compared with TURP } \\
\text { Only in units where the work up and follow up is performed by urologists working } \\
\text { collaboratively with trained interventional radiologists }\end{array}$ \\
\hline \multirow[t]{3}{*}{$\begin{array}{l}\text { Mini invasive simple } \\
\text { prostatectomy }\end{array}$} & EAU 2020 & $\begin{array}{l}\text { Prostate volume }>80 \mathrm{~cm}^{3} \\
\text { However, RCTs are needed }\end{array}$ \\
\hline & AUA 2019 & NA \\
\hline & NICE 2015 & NA \\
\hline \multirow[t]{3}{*}{$\begin{array}{l}\text { Intra-prostatic } \\
\text { injections }\end{array}$} & EAU 2020 & $\begin{array}{l}\text { Do not offer intraprostatic Botulinum toxin-A injection treatment to patients with male } \\
\text { LUTS }\end{array}$ \\
\hline & AUA 2019 & NA \\
\hline & NICE 2015 & Consider offering botulinum toxin injection into the prostate only as part of a RCT \\
\hline
\end{tabular}

tates with minor differences. The EAU mentioned open SP when EEP was not available. The AUA suggests considering open, laparoscopic or robotic assisted SP, depending on the surgeon expertise. The NICE guideline stated open SP as an alternative to TURP, TUVP or HoLEP.

\section{Enucleation}

The EAU and AUA working groups offer enucleation for patients with prostate size $>80 \mathrm{~cm}^{3}$. EAU stated that Holmium laser enucleation (HoLEP) is the current standard for large prostates and is an alternative to TURP or 
Table 3 (continued)

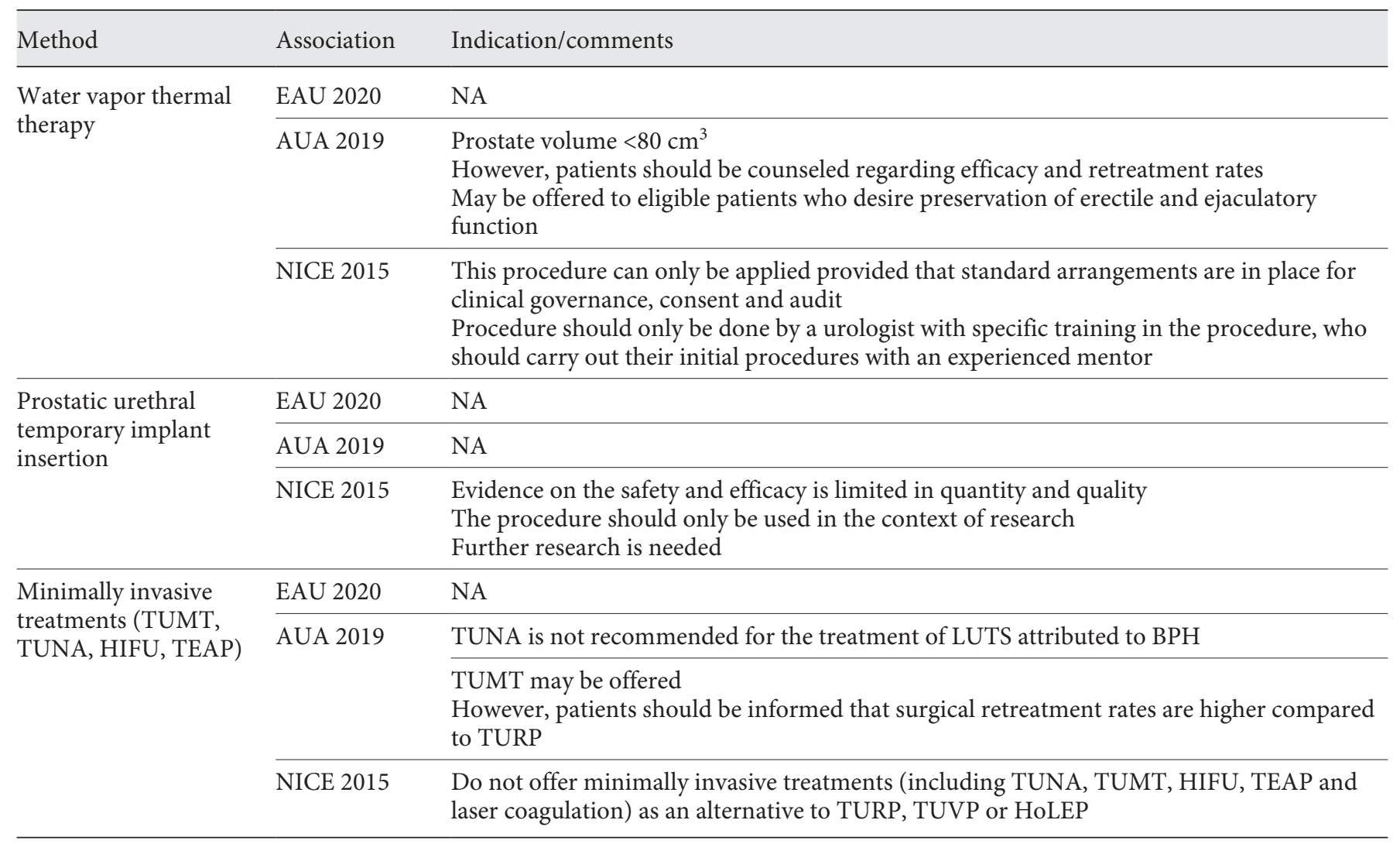

HIFU, High-intensity focused ultrasound; HoLEP, Holmium laser enucleation of the prostate; LUTS, Lower Urinary Tract Symptoms; PAE, Prostatic artery embolization; RCT, Randomized clinical trial; TEAP, Transurethral ethanol ablation of the prostate; TUMT, Transurethral microwave thermotherapy; TUNA, Transurethral needle ablation; TURP, Transurethral resection of the prostate; TUVP, Transurethral Vaporization of Prostate; AUA, American Urological Association; EAU, European Association of Urology; NICE, National Institute for Health and Care Excellence.

open SP. According to European recommendations, specialists can also use diode or thulium laser for enucleation, the latter being an alternative to HoLEP. The AUA recommends HoLEP and thulium laser enucleation (ThuLEP) as prostate size-independent procedures. The NICE guidelines are not very specific when it comes to recommendations regarding laser enucleation methods.

\section{Surgical Treatment for Patients on Antithrombotic} Agents (Table 2)

The EAU and AUA recommend laser treatment (enucleation or vaporization) for patients on anticoagulant/ antiplatelet therapy. Similarly, the EAU recommends laser modalities: HoLEP, vapoenucleation and vaporesection with Tm:YAG laser and vaporization with 532-nm Potassium-Titanyl-Phosphate (KTP) or 532-nm Lithium
Borat (LBO) lasers. The NICE team discusses the implementation of GreenLight XPS as a possible option but notices that there is insufficient high-quality evidence.

\section{Minimally Invasive Interventions (Table 3)}

\section{Prostatic Urethral Lift (PUL)}

All associations offer PUL with some variations in indications, a permitted prostate size being one of them. The EAU recommends $<70 \mathrm{~cm}^{3}$, the AUA- $<80 \mathrm{~cm}^{3}$ and the NICE- $<100 \mathrm{~cm}^{3}$. The AUA also points to the need for informing the patients about PUL's inferiority to TURP. Where the NICE guideline is concerned, PUL is thought to be suitable for men older than 50 .

\section{Aquablation/Waterjet Ablation}

The EAU and AUA offer waterjet ablation (aquablation) as a treatment option for men with prostate volume 
$30-80 \mathrm{~cm}^{3}$, but both guidelines highlight the lack of longterm follow up data. The NICE guideline recommends water jet ablation as 1 possible option. The association states that the evidence on efficacy is limited, that the procedure should only be done within clinical trials settings.

\section{Prostatic Artery Embolization (PAE)}

The EAU guideline recommends PAE for patients who want to consider minimally invasive treatment options despite less optimal objective outcomes compared with TURP. The AUA considers PAE only for clinical trials. The NICE indications are similar to the EAU.

\section{Intra-Prostatic Injections}

Both the EAU and NICE make mention of intra-prostatic injections. Whereas the EAU discarded intraprostatic Botulinum toxin-A injection, the NICE guideline offers it only as a part of a RCT. The AUA does not discuss it.

\section{Water Vapor Thermal Therapy}

The AUA team states that it is a suitable option for patients with a prostate volume $<80 \mathrm{~cm}^{3}$, and for those who have already been informed about its safety and efficacy and want to preserve their sexual function. The NICE guideline points out that the procedure should only be done by specifically trained urologists. The EAU states that randomized controlled trials against a reference technique are needed to confirm the first results.

Prostatic Urethral Temporary Implant Placement

The NICE working group proposes using a prostatic urethral temporary implant only within clinical trials because the evidence on the safety and efficacy is limited in terms of its quantity and quality. The EAU and AUA do not discuss this procedure.

Other Minimally Invasive Treatments

Besides the abovementioned methods, the AUA recommends using transurethral microwave thermotherapy (TUMT) only for patients who have been informed that surgical retreatment rates are higher compared to TURP. It also does not recommend transurethral needle ablation (TUNA). The NICE guideline does not offer TUMT, TUNA, high-intensity focused ultrasound (HIFU), transurethral ethanol ablation of the prostate (TEAP) as an alternative to TURP, TUVP or HoLEP. The EAU makes no mention of them.

\section{Discussion}

To our knowledge, this study is the first to evaluate the development and reporting quality of CPG, as proposed by the AGREE-II tool [5]. Our review focused on the most recent updates of the international association guidelines [6-8]. The overall scores for the guidelines showed that all 3 guidelines are being rigorously developed and serve as examples of well-designed CPGs. The NICE scored best with $91.6 \%$, whereas the EAU and AUA scored 79.1 and $83.3 \%$, respectively.

The guidelines aim to improve the quality of patient care and reduce unnecessary differences in practice [11]. The main target audience for the guidelines are urologists, therefore in our study we purposefully included practicing urologists without any other specific qualification (e.g., in field of linguistics or data analysis) to appraise the guidelines. Amongst the 6 parameters assessed with AGREE II, the overall domain scores for clarity of presentation were the highest $(80.6 \%)$ with minor variance between the 3 guidelines. This domain represents how the CPGs are dealing with the main goal-reporting effective treatment options for different patients. We believe that despite lower scores in other domains, a high score in this field signifies the clinical importance of all the guidelines (EAU-91.7\%; AUA-80.6\%; NICE-79.2\%). The domains relating to editorial independence, scope and purpose yielded the second and third best scores respectively.

One of the least scored domains was "Applicability" with a score of 33.3\% (EAU-32.3\%; AUA-33.3\%; NICE$56.3 \%)$. The latter is the anticipated finding as most of the guideline development groups did not indicate the barriers or facilitators to implementing guideline recommendations and did not provide ways to audit effective implementation. Being a secondary goal in guideline development, the applicability is an important point that should be considered by the Panels. However, the applicability of the guidelines is not limited to methods of implementation and as suggested by Speakman et al. [12] should include a discussion of how Panels evaluate new methods. The authors believe that this may result in minimizing the misuse under commercial pressure, particularly in private healthcare centers [12].

The domain stakeholder involvement was also ranked low with a score of $50.0 \%$ (EAU-25.0\%; AUA-50.0\%; NICE-61.1\%). After the evaluation process, we found that most guidelines did not highlight the views and preferences of the target population and did not clearly define the target users. The NICE guidelines reported the broad- 
est spectrum of Panel participants and were more precise in defining target users. The absence of precise data on stakeholder involvement should not be considered a major limitation to the guidelines, but it could significantly improve the applicability of the guidelines for patients.

The stakeholder involvement and applicability domains were also ranked lowest in the study of $\mathrm{Xu}$ et al. [13], who compared guidelines on a1-blockers and $5 \alpha$-reductase inhibitors administration. The lack of target population views and implementation mechanisms were described by Gupta et al. [14] in assessing the prostate cancer guidelines (stakeholder involvement and applicability were also ranking lowest). Discussing guidelines on smoking cessation, Sharma et al. [15] assign 54.2 and $33.3 \%$ respectively for the rigour of development and editorial independence domains. Such consistency in CPGs design may signify another important limitation to modern medical practice-we are more prone to focus on the estimated efficacy and percent of complications rather than report the actual needs of the population.

The differences in surgical options among the included guidelines were insignificant. First, each association recommends a different range of methods. Such discrepancies could emerge because the working groups had used different search strategy and included different studies for evidence synthesis. The EAU selected strictly systematic reviews, RCTs and prospective non-randomized comparative studies. The AUA, in addition to the abovementioned, also included observational and clinical controlled trials. The NICE guidelines did not limit search strategy and used free-text terms. This differences in approaches have been previously mentioned by Speakman et al. [12] where they discussed how the EAU panel evaluates papers. Such a rigorous approach to selecting and assessing articles allowed EAU scored first in the domain of clarity of presentation. The second possible reason for the differences is the updating process. The EAU CPG are only being updated annually.

The EUA CPG 2021 have been released recently. No changes in methodology or editorial board comparing with the previous year guidelines took place, thus the newest guidelines obviously have the same score for domains $1-3$ and 6 . The main change in terms of surgical treatment was restructuration of the section: while previous year it was divided according to specific technologies, no they are grouped depending on the surgical technique as follows: resection, enucleation, vaporization, alternative ablative techniques. The same urologists ranked this new edition of EAU guidelines for domain 4 and 5 and got the same results as for the previous version.
The AGREE tool was elaborated in 2003 as an instrument for CPG evaluation [4] and has been amended recently $[5,16,17]$. Unfortunately, high AGREE II scores do not guarantee high quality of CPGs. Despite the presence of high and rather low ranked domains, the included guidelines are of high-quality and clearly reflected all the relevant information about $\mathrm{BPH}$ treatment. Notwithstanding, using many appraisal tools, AGREE II was shown to be a reliable assessment instrument with the highest potential [18].

This study has several limitations. Firstly, CPGs were appraised only by urologists. However, it should be borne in mind that it was a large team comprising both less- and highly experienced specialists. Secondly, the AGREE II tool is not an ideal instrument, but it remains one of the most reliable. The inability to distinguish significant differences between 2 similar scores is one of the major limitations of the AGREE II, and the only reliable threshold suggested is $60 \%$ distinguishing between low and acceptable levels.

\section{Conclusions}

The analyzed CPGs comprehensively highlight the minimally invasive and surgical treatment options for $\mathrm{BPH}$. According to the AGREE II tool, the domains for clarity of presentation and editorial independence received the highest scores. The stakeholder involvement and applicability domains were ranked as the lowest. Improving the CPG in these domains may help to improve the clinical utility and applicability of CPGs.

\section{Statement of Ethics}

The paper is exempt from ethical committee approval because this study is a literature review and did not involve humans or animals.

\section{Conflict of Interest Statement}

The authors have stated explicitly that there are no conflicts of interest in connection with this article.

\section{Funding Sources}

This research did not receive any specific grant from funding agencies in the public, commercial, or not-for-profit sectors. 


\section{Author Contributions}

D. Enikeev: Data analysis, Protocol development. V. Misrai: Manuscript editing. E. Rijo: Manuscript editing. R. Sukhanov: Data collection, Manuscript editing. D. Chinenov: Data collection, Manuscript editing. M. Gazimiev: Data collection, Manuscript editing. M. Taratkin: Data analysis, Manuscript writing. C. Azilgareeva: Data analysis, Manuscript writing. A. Morozov: Data analysis, Manuscript editing. T.R.W. Herrmann: Manuscript editing. P. Glybochko: Protocol development, Manuscript editing.

\section{Data Availability Statement}

Data are available on demand.

\section{References}

1 Takamori H, Masumori N, Kamoto T. Surgical procedures for benign prostatic hyperplasia: a nationwide survey in Japan, 2014 update. Int J Urol. 2017;24(6):476-7.

2 Morton A, Williams M, Perera M, Teloken $\mathrm{PE}$, Donato $\mathrm{P}$, Ranasinghe S, et al. Management of benign prostatic hyperplasia in the 21st century: temporal trends in Australian population-based data. BJU Int. 2020; 126(Suppl 1):18-26.

3 Malaeb BS, Yu X, McBean AM, Elliott SP. National trends in surgical therapy for benign prostatic hyperplasia in the United States (2000-2008). Urology. 2012;79(5):1111-6.

4 Cluzeau F, Burgers J, Brouwers M, Grol R, Mäkelä M, Littlejohns P, et al. Development and validation of an international appraisal instrument for assessing the quality of clinical practice guidelines: the AGREE project. Qual Saf Health Care. 2003;12(1):18-23.

5 Koufogiannakis D, Brettle A. Agree. In Being evidence based in library and information practice. Facet; 2018. p. 59-70.

6 Gravas S, Cornu JN, Gacci M, Gratzke C. EAU Guidelines. Management of non-neurogenic male LUTS. 2019 Jun. p. 10-2.

7 Foster HE, Dahm P, Kohler TS, Lerner LB, Parsons JK, Wilt TJ, et al. Surgical management of lower urinary tract symptoms attributed to benign prostatic hyperplasia: Aua guideline amendment 2019. J Urol. 2019; 202(3):592-8.
8 National Institute for Health and Care Excellence. The management of lower urinary tract symptoms in men produced by the National Clinical Guideline Centre. 2010. p. 353.

9 Doniselli FM, Zanardo M, Manfrè L, Papini GDE, Rovira A, Sardanelli F, et al. A critical appraisal of the quality of low back pain practice guidelines using the AGREE II tool and comparison with previous evaluations: a EuroAIM initiative. Eur Spine J. 2018;27(11): 2781-90.

10 Sekercioglu N, Al-Khalifah R, Ewusie JE, Elias RM, Thabane L, Busse JW, et al. A critical appraisal of chronic kidney disease mineral and bone disorders clinical practice guidelines using the AGREE II instrument. Int Urol Nephrol. 2017;49(2):273-84.

11 Chen Q, Lu W, Kupelian P, Langen K, Meeks S, Ruchala K, et al. SU-FF-J-85: automatic seed detection in MVCT images for prostate radiotherapy. Med Phys. 2005;32(6):1939.

12 Speakman MJ, Cornu JN, Gacci M, Gratzke C, Mamoulakis C, Herrmann TRW, et al. What is the required certainty of evidence for the implementation of novel techniques for the treatment of benign prostatic obstruction? Eur Urol Focus. 2019;5(3):351-6.
13 Xu X-F, Liu G-X, Zhu C, Qiao X-M, Yu S-F, Deng T, et al. al-Blockers and 5a-reductase inhibitors are the most recommended drugs in treating benign prostatic hyperplasia: an evidence-based evaluation of clinical practice guidelines. Front Pharmacol. 2020;11:311.

14 Gupta M, McCauley J, Farkas A, Gudeloglu A, Neuberger MM, Ho YY, et al. Clinical practice guidelines on prostate cancer: a critical appraisal. J Urol. 2015;193(4):1153-8.

15 Sharma R, Alla K, Pfeffer D, Meurk C, Ford P, Kisely S, et al. An appraisal of practice guidelines for smoking cessation in people with severe mental illness. Aust N Z J Psychiatry. 2017;51(11):1106-20.

16 Brouwers MC, Kho ME, Browman GP, Burgers JS, Cluzeau F, Feder G, et al. Development of the AGREE II, part 1: performance, usefulness and areas for improvement. CMAJ. 2010; 182(10):1045-52.

17 Brouwers MC, Spithoff K, Kerkvliet K, Alonso-Coello P, Burgers J, Cluzeau F, et al. Development and validation of a tool to assess the quality of clinical practice guideline recommendations. JAMA Netw Open. 2020;3(5): e205535.

18 Vlayen J, Aertgeerts B, Hannes K, Sermeus W, Ramaekers D. A systematic review of appraisal tools for clinical practice guidelines: multiple similarities and one common deficit. Int J Qual Health Care. 2005;17(3):235-42. 